NBER WORKING PAPER SERIES

\title{
THE CHOICE OF MONETARY INSTRUMENT \\ IN TWO INTERDEPENDENT ECONOMIES \\ UNDER UNCERTAINTY
}

\author{
Stephen J. Turnovsky \\ Vasco d'orey
}

Working Paper No. 2604

NATIONAL BUREAU OF ECONOMIC RESEARCH
1050 Massachusetts Avenue
Cambridge, MA 02138
June 1988

The research supported here is part of the NBER's research program in International studies. Any opinions expressed are those of the authors and not those of the National Bureau of Economic Research. 
NBER Working Paper \#2604

June 1988

\title{
THE CHOICE OF MONETARY LNSTRUMENT IN TWO INTERDEPENDENT ECONOMIES LNDER UNCERTANTTY
}

\begin{abstract}
This paper analyzes the choice of monetary instrument in a stochastic two country setting where each country's set of monetary policy instruments includes both the money supply and the interest rate. It shows bow the optimal choice of instrument is determined in two stages. First, for each pair, the minimum welfare cost for each economy is determined. This defines a pair of payoff matrices and the second stage involve determining the Nash equilibrium for this bimatrix game. In our illustrative example for the alternative shocks considered, a dominant Nash equilibrium is always obtained.
\end{abstract}

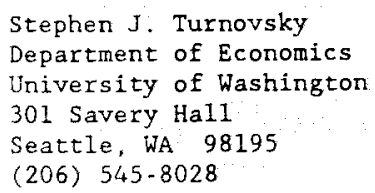

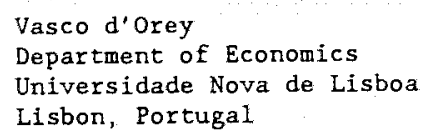




\section{INTRODLCTION}

The question of the optimal choice of monetary instrument was first introduced into tine macrostabilization literature by Poole (1970) and has been extensively discussed since. The key conclusion is that in a world of uncertainty, the superiority of the money stock or incerest rate as the operating target depends upon the sources of the stochastic disturbances impinging on the economy.

A crucial assumption underlying this literature is the presence of only a single policy maker. Poole's original analysis, and much of the derivative work, deals with a closed economy, in which this assumption is the obvious one. Likewise, the international extensions are typically to small open economies, in which the policy maker can ignore the repercussions of his actions on the rest of the world. However, much of the recent work in international monetary policy stresses the increasing interdependence between economies and policy making. Disturbances and policy actions occurring in one country exert influences abroad, thereby inducing policy reactions, which in turn feed back on the first economy. Monetary policy therefore involves important strategic considerations. Beginning with early work by Hamada (1976), more recent authors such as Canzoneri and Gray (1985) and others have analyzed strategic monetary policy under alternative behavioral assumptions.

The present paper analyzes the choice of monetary instrument in a stochastic two-country setting: As will become evident, the nature of the monetary instrument in a two country environment is of second order of dimensionality. Specifically, each country's set of policy instruments includes both the money supply and the interest rate. The monetary instrument problem therefore involves assessing welfares in situations where the monetary authorities choose to set different policy instruments, as well as in cases where the same instrument is selected. These various combinations of instrument choice give rise to a pair of $2 \times 2$ payoff matrices in welfare costs and we treat the monetary instrument problem as being to determine the equilibrium outcome to this bimatrix game ${ }^{+}$ 


\section{THE ANALYTICAI FRAMEVORK}

The analysis is based on a two country stochastic macroeconomic model. In which both economies are subject to real and nominal disturbances and expectations are rational 2 in order to maximize analytical tractability, the simplest such model is used. Specincally we consider two identical economies, each producing a common traded good and trading a single common bond. Purchasing power parity (PPP) and uncovered interest parity are therefore assumed to hold. In deviation form, the model is expressed by the following equations:

$$
\begin{gathered}
P_{t}=P_{t}^{*}+E_{t} \\
Y_{t}+Y_{t}^{*}=d_{1}\left(Y_{t}+Y_{t}^{*}\right)-d_{2}\left[I_{t}-\left[\varepsilon_{t}\left(P_{t+1}\right)-P_{t}\right]\right] \quad 0<d_{1}<1 \\
-d_{2}\left[I_{t}^{*}-\left[\varepsilon_{t}\left(P_{t+1}^{*}\right)-P_{t}^{*}\right]\right]+z_{t} \quad d_{2}>0 \\
M_{t}-P_{t}=\alpha_{1} Y_{t}-\alpha_{2} I_{t}+v_{t} \quad \alpha_{1}>0, \quad \alpha_{2}>0 \\
M_{t}^{*}-P_{t}^{*}=\alpha_{1} Y_{t}^{*}-\alpha_{2} I_{t}^{*}+v_{t}^{*} \\
I_{t}=I_{t}^{*}+\varepsilon_{t}\left(E_{t+1}\right)-E_{t} \\
Y_{t}=\gamma\left[P_{t}-\varepsilon_{t-1}\left(P_{t}\right)\right]+w_{t} \\
Y_{t}^{*}=\gamma\left[P_{t}^{*}-\varepsilon_{t-1}\left(P_{t}^{*}\right)\right]+w_{t}^{*}
\end{gathered}
$$

where

$Y=$ Real output in logarithms, measured as a deviation about its natural rate level, $P=$ price of domestic output, expressed in logarithms,

$E=$ exchange rate (measured in terms of units of domestic currency per unit of foreign currency), expressed in logarithms,

$I=$ nominal interest rate, expressed in natural units,

$M=$ nominal money supply, expressed in logarithms, 
$\varepsilon_{t}=$ expectation, conditioned on information at time $t$

$u_{t}=$ stochastic disturbance in the world demand for output,

$v_{t}=$ stochastic disturbance in the demand for money:

$w_{t}=$ stochastic disturbance in supply.

Domestic variables are unstarred; foreign variables are denoted with asterisks.

Equation (1) describes purchasing power parity, assumed to hold between domestic and foreign goods. Equation (2) describes equilibrium in the world goods market, where world demand depends upon world output, the real interest rates in the two economies, and the stochastic disturbance in demand. The money market equilitrium conditions in the two countries are standard and described by (3) and $\left(3^{\prime}\right)$ respectively. The perfect substitutability between domestic and coreign bonds is described by the interest parity condition (4). Finally, equations (5) and $\left(5^{\prime}\right)$ describe outputs in the two economies in terms of standard Lucas supply functions the deviation in out put from its natural rate is postulated to be a positive function of the unanticipated movement in the price of output, together with the stochastic disturbance in supply. The stochastic variables, $u_{\ell}, v_{t}^{*}, w_{t}, w_{t}^{*}$, are asumed to be independently distributed with zero means and finite variances, denoted by $\sigma_{u}^{2}, \sigma_{v}^{2}$, etc. If, in addition, as in fact turns out to be the case, the optimal choices of policy instruments are fixed over time, then, as is well known, the rational expectations golution to the system (1) - (5) implies that expectations for all future periods are constant. With the system specified in deviation form; this constant is zero, so that

$$
\varepsilon_{t}\left(P_{t+1}\right)=\varepsilon_{t}\left(P_{t+1}^{*}\right)=\varepsilon_{t}\left(E_{t+1}\right)=0
$$

Equations (1) - (6) describe the structure of the two economies. The policy makers in these economies are assumed to take as benchmarks, the level of output in a frictionless economy, one where wages and prices are fully flexible and the labor market clears. As is shown in the Appendix, assuming that labor is immobile internationally, the output in such an economy, responds only to its own supply shocks. In terms of the present notation this adjustment can be expressed as

$$
\tilde{Y}_{t}=k w_{t}, \quad \tilde{Y}_{t}^{*}=k w_{t}^{*}, k \equiv \frac{(1+n)}{1+n+\gamma}<1
$$

where $n$ is the elasticity of supply of labor. The level of output fluctuates less than proportionately 
with the supply disturbance. Thus the respective objective functions of the two policy makers are taken to be to minimize. ${ }^{3}$

$$
\begin{aligned}
& \Omega_{t} \equiv E_{t-1}\left(Y_{t}-\tilde{Y}_{t}\right)^{2} \\
& \Omega_{t}^{*} \equiv E_{t-1}\left(Y_{t}^{*}-\tilde{Y}_{t}^{*}\right)^{2}
\end{aligned}
$$

These objective functions are assumed to be optimized through monetary policy, which we assume can be conducted either by controlling the money supplies or by setting the interest rates. Our concern is to compare the alternative approaches and to detemine the nature of the "monetary instrument problem confroating policy makers whin strategic context. To do this requires us to obtain alternative reduced form solutions, appropriate for ach chosen combination of monetary instruments.

\section{A. Reduced Fopm Under Money Supply Instruments}

When both policy makers use the nominal money supply th their respective monetary inster. ments, the solutions for $Y_{t}$ and $Y_{t}$ are

$$
\begin{aligned}
& Y_{t}=a_{t}\left(M_{t}-v_{t}\right)+a_{v}^{*}\left(M_{t}^{*}-v_{t}^{*}\right)+a_{u} u_{t}+a_{v} w_{t}+a_{v}^{*} w_{t}^{*} \\
& Y_{t}^{*}=a_{v}^{*}\left(M_{t}-v_{t}\right)+a_{v}\left(M_{t}^{*}-v_{t}^{*}\right)+a_{u} u_{t}+a_{w}^{*} w_{t}+a_{v} w_{i}^{*}
\end{aligned}
$$

where

$$
\begin{gathered}
a_{v} \equiv \frac{\gamma}{2}\left[\frac{d_{3}}{D_{M}}+\frac{1}{1+\alpha_{2}+\alpha_{1} \gamma}\right]>0 ; \quad a_{v}^{*}=\frac{\gamma}{2}\left[\frac{d_{2}}{D_{M}}-\frac{1}{1+\alpha_{2}+\alpha_{1} \gamma}\right]<0 \\
a_{u}=\frac{\alpha_{2} \gamma}{2 D_{M}}>0, a_{v}=\frac{\left(1+a_{2}\right) a_{v}}{\gamma}>0, a_{w}^{*}=\frac{\left(1+\alpha_{2}\right) a_{v}^{*}}{\gamma}<0 \\
D_{M} \equiv d_{2}\left[1+\alpha_{2}+\alpha_{1} \gamma\right]+\gamma \alpha_{2}\left(1-d_{1}\right)>0 .
\end{gathered}
$$




\section{B. Reduced Form Under Interest Rate Instrument}

When the nominal interest rates are the policy instruments used by the policy makers, the money market equations $(3)$ and $\left(3^{\prime}\right)$ become irrelevant and the solutions for $Y_{t}$ and $Y_{t}^{*}$ become ${ }^{5}$

$$
Y_{t}=b_{I} I_{t}+b_{i}^{*} I_{t}^{*}+b_{u} w_{t}+b_{w} w_{t}+b_{w}^{*} w_{t}^{*}
$$

$$
Y_{t}^{*}=b_{I}^{*} I_{t}+b_{I} I_{t}^{*}+b_{u} u_{t}+b_{w}^{*} w_{t} \div b_{w} w_{t}^{*}
$$

where

$$
\begin{aligned}
& b_{I}=-\frac{\gamma}{2}\left[\frac{d_{2}}{D_{I}}+1\right]<0 ; \quad b_{I}^{*}=\frac{\gamma}{2}\left[1-\frac{d_{2}}{D_{I}}\right]>0 \\
& b_{u}=\frac{\gamma}{2 D_{I}}>0 ; \quad b_{w}=-\frac{b_{I}}{\gamma}>0 ; \quad b_{w}^{*}=-\frac{b_{I}^{*}}{\gamma}<0 \\
& D_{I} \equiv \gamma\left(I-d_{1}\right)+d_{2}>0
\end{aligned}
$$

\section{Reduced Form Under Asymmetric Choice of Instruments}

With respect to asymmetric instrument choice, it suffices to consider the case where the domestic monetary authority choosed the money stock as the policy variable while the foreign monetary authority sets the interest rate. The reverse pairing of instruments is analogous. The solutions for $Y_{t}$ and $Y_{t}^{*}$ now become:

$$
\begin{aligned}
& Y_{t}=c_{v}\left(M_{t}-v_{t}\right)+c_{I}^{*} I_{t}^{*}+c_{u} u_{t}+c_{w} w_{t}+c_{w}^{*} w_{t}^{*} \\
& Y_{t}^{*}=e_{v}\left(M_{t}-v_{t}\right)+e_{I}^{*} I_{t}^{*}+e_{u} u_{t}+e_{w} w_{t}+e_{w}^{*} w_{t}^{*}
\end{aligned}
$$


where

$$
\begin{aligned}
& c_{v}=\frac{\gamma}{\eta}\left[2 d_{2}+\gamma\left(1-d_{1}\right)\right]>0 \quad c_{I}^{*}=\frac{\gamma^{2}}{\eta} \alpha_{2}\left(1-d_{1}\right)>0 \\
& c_{u}=\frac{\gamma \alpha_{2}}{\eta}>0 ; \quad c_{u}=\frac{\left(1+\alpha_{2}\right) c_{v}}{\gamma}>0 ; \quad c_{w}^{*}=-\frac{c_{I}^{*}}{\gamma}<0 \\
& e_{\eta}=-\frac{\gamma^{2}\left(1-d_{1}\right)}{\eta}<0 ; \quad e_{I}^{*}=-\frac{\gamma}{\eta}\left[2 d_{2}\left(1+\alpha_{2}+\alpha_{1} \gamma\right)+\gamma \alpha_{2}\left(1-d_{1}\right)\right]<0 \\
& e_{u}=\gamma \frac{\left(1+\alpha_{2}+\gamma \alpha_{1}\right)}{\eta}>0 ; \quad e_{w}=\frac{\left(1+\alpha_{2}\right) e_{v}}{\gamma}<0 ; \quad e_{w}^{*}=-\frac{e_{l}^{*}}{\gamma}>0 \\
& \eta \equiv 2 d_{2}\left[1+\alpha_{2}+\gamma \alpha_{1}\right)+\gamma\left(1-d_{1}\right)\left(1+2 \alpha_{3}+\gamma \alpha_{1}\right)>0
\end{aligned}
$$

Space limitations preclude detailed discussion of these reduced forms, which in any event are straightorward. However, several observations are worth making. First, the impacts of exogenous shocks on the two economies depend upon the chosen monetary policy choice. Secondly, in the two cases of identical instrument choice, the symmetry of the undetying economies is reflected in the symmetry of the reduced form solutions. The cross country effects of policy on outputs are negative. This is the "negative transmission" mechanism dating back to Mundell (1963) and which under PPP is at its most potent. Essentially, monetary expansion abroad say, leads to a nominal depreciation of the foreign currency, i.e. and appreciation of the domestic currency. This in turn leads to a decline in the domestic price level, as PPP is restored, leading to a reduction in domestic output. Finally, with asymmetric choice of instruments, this symmetry is lost.

\section{DETERMMNATION OF STRATEGIC EQUILIBRIA}

We now determine the strategic equilibrium under alternative assumptions regarding the choice of monetary policy instrument. We do so under the assumption of Cournot behavior, in which each policy maker takes the behavior of his rival as given, and we allow for both the money supply and the interest rate to serve (alternative) policy instruments. Rather than discussing each case in turn, the general spproach is outlined.

First, substitute for $Y_{t}$ and $Y_{t}^{*}$ from the reduced forms and for the frictionless output levels $\bar{Y}_{t}, \tilde{Y}_{t}^{*}$ from $(7)$ into the welfare functions $(8),\left(8^{\prime}\right)$. Taking expected values, in general these are seen to be quadratic functions of the form 


$$
\begin{aligned}
& \Omega=\Omega\left(i, i^{*}, \sigma_{z}^{2}\right) \\
& \Omega^{*}=\Omega\left(i, i^{*}, \sigma_{z}^{2}\right)
\end{aligned}
$$

where $\sigma_{x}^{2}$ denotes the vector of variances and covariances of the stochastic disturbances. Henceforth time subscripts are dropped and $i, i^{*}$, index the choice of policy instruments in the domestic and foreign economies, respectively. Specifically, $i=M, I$, and $i^{*}=M^{*}, I^{*}$, giving rise to the four possible combinations of instrument choice.

The optimality conditions are obtained by minimizing (12) with respect to $i,\left(12^{\prime}\right)$ with respect to $i^{*}$. Under the assumption of Cournot behavior, this yields

$$
\frac{\partial \Omega}{\partial i}=0=\frac{\partial \Omega^{*}}{\partial i}
$$

Given the quadratic welfare functions, these equations are linear in the policy instruments and define each country's reaction function, the slopes of which depend upon the policy choice. In all cases, since the random variables are independently distributed over time, the optimum calls for setting $i=i^{*}=O\left(i=M, I_{i} i^{*}=M^{*}, I^{*}\right)$. Substituting these values back into (12), (12') yields the minimized welfare costs under the different regimes.

\section{CHOICE OF MONETARY INSTRUMENT}

Table 1 summarizes the minimized welfare costs under the alternative instrument combinations in the form of a $2 \times 2$ payoff matrix for each country. The three parts of this table summarize the effects of: (i) monetary; (ii) real demand; and (iii) supply disturbances, each taken in turn. In all cases unit variances are assumed. The optimal choice of monetary instrument is defined to be the Nash equilibrium to this bimatrix game, in the sense that neither policy maker has an incentive to switch unilaterally from this point. The three disturbances shall be discussed in turn.

\section{A. Monetary Disturbances}

Consider first domestic monetary disturbances. It is clear from A(i) of the table that as long as the domestic monetary authority controls the domestic in terest, thereby allowing the domestic 
money supply to absorb fully the domestic monetary shock, output at home and abroad will be stabilized perfectly, irespective of the choice of monetary instrument abroad. Thus both the $I-M^{*}$ and the $I-I^{*}$ instrument combinations represent Sash equilibria. Moreover, both are admissible in the sense that neither is dominated by the other, in terms of welfare costs.

With a perfectly correlated worldwide monetary disturbance, it is clear that the $I-I^{*}$ instrument combinstion is ash equibrium, since both countries allow their respective money supplies to absorb their monetary shocks, thereby perfectly insulating the output levels in the two economias. This is a direct analogue of Poole. It is clear that neither the $M-I^{*}$ combination not the $I^{*}-M$ combintion can be a Nasb equibrium, since in either case the policy raike control ling the money supply can be made better of by swithing to setaing the interest rate. But it is interesting to note that it is possible for the $M-M^{*}$ combirstion to be a Nash equilibrium. This will be an if and only if $d_{2} n<\gamma\left(1-d_{1}\right) D_{M}$. While for plausible paraneter values this condition is unlikely to be met, it canno be ruled out (e.g. if $d_{z}=0$ ). Basically, the negative international transmission of monetary shocks means that the negtitye effects of domestic money demand shocks on domestic cutput are offset to some degree by the positive effects of the corresponding movements in the foreign disturbance. Under certain conditions these may be suffichtly large to eliminate the incentive for either policy maker to swith unilaterally to setting the interest zate. In this case, when $M-M^{*}$ is a Nagh equilibrium, it is generally inferior to both policy makers setting their respective interest rates. However, without cooperation, neither policy maker has the incentive to make this switch.

\section{E. Real Demand Disturbances}

These are straightforwad. Directly evaluating the terms appearing in the matrix, we can establish $b_{u}>c_{u} ; a_{u}<e_{y}$. This implies that the only Nash equilibrium is the $M-M^{*}$ policy combination. For any other policy combination the policy maker setting the interest rate would have an incentive to switch usilaterally to setting the money supply. The intuition is the same as in Poole. By controlling the money supply, the monetary authority allows some of the fuctuations in demand to be borne by the interest rate, thereby reducing the fuctuations in output. 


\section{Supply Disturbances}

Supply disturbances give rise to fluctuations in the frictionless level of output and we therefore measure deviations in output about $k w_{t}, k w_{t}^{*}$, where $k=\frac{1+n}{1+n-y}<1$. Turning first to domestic disturbances, we can show that $e_{w}^{2}>a_{w}^{* 2} ; b_{w}^{* 2}>c_{w}^{* 2}$. It therefore follows that setting its money supply dominates setting the interest rate insofar as the foreign economy is concerned. Intuitively, a positive shock in $w_{t}$ raises $Y_{t}$, lowers $P_{t}$ and hence foreign output $Y_{t}^{*}$. If the foreign monetary authority pegs the money supply some of the fluctuations in the world output market are borne by the interest rate $I_{t}^{*}$ and less by $Y_{t}^{*}$ if it pegs $I_{t}^{*}$ the fuctuations are more fully borne by $Y_{i}^{*}$

Given that the foreign economy chooses to set its money stock, the optimal choice in the domestic economy depends upon whether

$$
\left(a_{w}-e_{w}^{*}\right)\left(a_{w}+e_{w}^{*}-2 k\right) \leqslant 0
$$

In fact, either inequality in (14) may hold, depending upon parameter values. For example, suppose $d_{1}=.75, d_{2}=.5, \alpha_{1}=1, \alpha_{2}=.5, \gamma=1$ are taken as reasonable values implying $a_{w}=.573, e_{w}^{*}=$ $.807{ }^{7}$ In this case, the $M-M^{*}$ combination is chosen if and only if $k<69$, i.e., if and only if the elasticity of supply of labor $n<1.23$; otherwise, the domestic authorities choose to set the interest rate, in which case the Nash equilibrium is the $I-M^{*}$ policy combination. The key to the choice here is which policy regime "tracks" the frictionless output level better. With $n$ large, the frictionless output is more sensitive to domestic supply shocks. For this particular parameter set this is more closely followed by setting $I$, but this is not true in all cases.

Finally, C(ii) summarizes the welfare costs for worldwide supply disturbances. In this case one can establish that both the $M-M^{*}$ and the $I-I^{*}$ policy combinationg are Nash equilibria in that starting from either, neither policy maker has an incentive to deviate unilaterally. However, one of the two equilibria can always be shown to be superior. Which one it is, depends critically upon parameter values. For the above set, $M-M^{*}$ is superior for $n<.538$, while $I-I^{*}$ dominates for $n>.538$. Since both policy makers have symmetric welfare costs in this case, there is no potential conflict in the choice of these two Nash equilibria. But it is passible for the inferior Nash equilibrium to be chosen and for the policy makers to be unable to coordinate their actions to attain the dominant outcome. In this case, some form of communication between the policy 
makers, as suggested by Farrell (1987) may induce the dominant Nash equibrium to be selected.

\section{CONCLUSIONS}

We have shown exactly how the optimal choice of monetary instrument in two interdependent economies is determined in tro stages. First, for each pair of policy instruments, the minimized welfare costs fot each sconomy are determined. This defines a pair of payof matrices and the second stage involves determining the Nash equilibrium pair of instruments for this bimatrix game.

To illustrate the procedure we bave chosen the simplest model of two symmetric economies. In all cases a dominant Nash equilibrium has been obtained But it is possible, particularly with asymmetric economies, for no equilibrium in pure strategies to exist. la such cases there will always be a solution in mixed strategies. This will involve each policy maker switching between the two instrumente th probabilities determined by the gane. It is also possible for multiple Nash equilibria to exist in which there are conflicts with respect to the welfares for the two agents. In this case the cutcome may not be an equilibium one unless there is some form of cooperation. These are interesting issues and merit further consideration. 


\section{APPENDIX \\ DERTVATION OF EQUATION (7) OF TEXT}

The derivations for the domestic and foreign economies are ansiogous and we shall focus on the former. Suppose that output is specified by the Cobb-Douglas production function, expressed logarithmically by

$$
Y_{t}=(1-\theta) N_{t}+\epsilon_{t}
$$

where $\epsilon_{t}$ is a productivity shock and $N_{t}$ denotes the logarithm of employment. The demand for labor under frictionless conditions, $\tilde{N}_{t}^{t}$, is determined by the marginal product condition

$$
\ln (1-\theta)-\theta \vec{N}_{t}^{d}+\epsilon_{\varepsilon}=W_{t}-P_{t}
$$

where $W$ denotes the logarithm of the nominal wage rate, while the supply of labor, $\tilde{N}_{t}^{s}$, under similar conditions is

$$
\tilde{N}_{t}^{t}=n\left(W_{t}-P_{t}\right)
$$

Assuming that labor is immobile internationally, labor market clearance in the domestic economy, characteristic of the frictionless economy, implies

$$
\tilde{N}_{t}^{d}=\tilde{N}_{t}^{a}=\bar{N}_{t}=\frac{n \ln (1-\theta)}{1+n \theta}+\frac{n}{1+n \theta} \epsilon_{t}
$$

so that output in the frictionlese economy is

$$
\bar{Y}_{t}=\frac{n(1-\theta) \ln (1-\theta)}{1+n \theta}+\left(\frac{1+n}{1+n \theta}\right) \epsilon_{\mathrm{q}}
$$

Now, the aggregate supply function (5) being assumed throughout the analysis, can be derived from the production function (A.1) if wages, instead of being perfectly flexible, are assumed to be determined by 8 one period contract, at 8 level such that the domestic labor market is expected to clear. The argument, familiar for a small open economy, applies directly to a large open economy 
in which labor is immobile internationally, as is being assumed ${ }^{8}$ In this case $\gamma$ and $w_{t}$ appearing in (5) are related to $\theta$ and $\epsilon_{t}$ appeariog in (A.1) by

$$
\gamma \equiv \frac{1-\theta}{\theta}, \quad w_{t} \equiv \frac{\epsilon_{t}}{\theta}
$$

Substituting for $\theta$ and $\epsilon_{t}$ from (A.5) into (A.4), and carrying out the same procedure for the foreign economy, the adjustments in the domestic and foreign frictionless economies expressed in deviation form are respectively

$$
\tilde{Y}_{t}=k w_{t}, \quad \tilde{Y}_{t}^{*}=k w_{t}^{*}, \quad k \equiv \frac{1+n}{1+n+\gamma}
$$

which is (7) of the text. 


\section{Table 1}

velfare Losses

A. (i) Domestic Monetary Disturbance $\left[\sigma^{2}=1\right]$

Domestic Economy

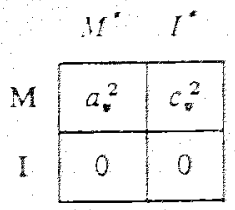

Foreign Economy

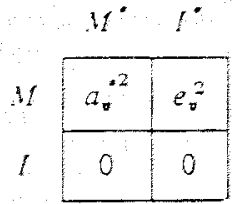

$l-M^{*}, l-l^{*}$ are Nash equilibria

A. (ii) Worldwide Monetary Disturbance $\left[\sigma_{*}^{2}=\sigma_{*}^{2}=\sigma_{m}^{*}=1\right]$

Domestic Economy

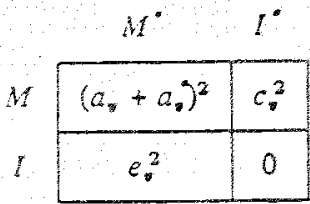

Foreign Economy

\begin{tabular}{|c|c|}
\hline$\left(a_{y}+a_{y}\right)^{2}$ & $e_{a}^{2}$ \\
\hline$c_{*}^{z}$ & 0 \\
\hline
\end{tabular}

$I-I^{*}$ is a Nash equilibrium; $M-M^{*}$ is a Nash equilibium in and only if $d_{2} \eta<\gamma\left(\frac{1}{2}-d_{1}\right) D_{M}$

B. Output Demand Disturbance $\left[\sigma_{z}^{2}=1\right]$

\begin{tabular}{|c|c|c|}
\hline & $M^{\circ}$ & $r^{\circ}$ \\
\hline$M$ & $a_{x}^{2}$ & $c_{\mathrm{v}}^{2}$ \\
\hline$I$ & $e_{z}^{2}$ & $b_{z}^{2}$ \\
\hline
\end{tabular}

Foreign Economy

\begin{tabular}{c|c|c|}
\multicolumn{1}{c}{$M^{2}$} & $I^{*}$ \\
\hline & $a_{*}^{2}$ & $e^{2}$ \\
\hline & $c_{\mathrm{s}}^{2}$ & $b^{2}$ \\
\hline
\end{tabular}

$M-M^{*}$ is Nash Equilibrium 


\section{C. (i) Domestic Supply Disturbance $\left[\begin{array}{r}3 \\ w\end{array}=1\right]$}

\begin{tabular}{c}
\multicolumn{2}{c}{ Domestic Economy } \\
$M^{*}$ \\
14 \begin{tabular}{c|c|}
$\left(a_{w}-k\right)^{2}$ & $\left(c_{w}-k\right)^{2}$ \\
\hline$\left(e_{w}^{*}-k\right)^{2}$ & $\left(b_{w}-k\right)^{2}$ \\
\hline
\end{tabular}
\end{tabular}

Furcign Economy

$M-M^{*}$ or $I-M^{*}$ is Nash equilibrium according to whether

$\left(a_{\infty}-e_{\infty}^{*}\right)\left(a_{\infty}+e_{\infty}^{*}-2 k\right) \lessgtr 0$; either case is possible.

C. (ii) Worldwide Supply Disturbance $\left[\sigma_{u}^{2}=\sigma_{y z}^{2}=\sigma_{\text {cro }}^{*}=1\right]$

\begin{tabular}{|c|c|c|c|c|}
\hline \multicolumn{2}{|c|}{ Domestic Economy } & & \multicolumn{2}{|c|}{ Foreign Economy } \\
\hline$M^{\circ}$ & $I^{*}$ & & $M^{*}$ & $I^{\circ}$ \\
\hline$\left(a_{*}+a_{*}^{*}-k\right)^{2}$ & $\left(c_{\omega}+c_{\omega}^{*}-k\right)^{2}$ & $M$ & $\left(a_{w}+a_{t}-k\right)^{2}$ & $\left(e_{w}+e_{w}^{\dot{v}}-k\right)^{2}$ \\
\hline$\left(e_{u}+e_{u}^{*}-k\right)^{2}$ & $\left(b_{*}+b_{*}^{*}-k\right)^{2}$ & $I$ & $\left(c_{w}+c_{0}^{2}-k\right)^{2}$ & $\left(b_{\omega}+b_{\omega}^{*}-k\right)^{2}$ \\
\hline
\end{tabular}

$M-M^{*}, I-I^{\circ}$ are Nash equilibria 


\section{FOOTNOTES}

- We are grateful to Matthew Canzoneri and the referee for their suggestions.

'This is similar to Hamada's (1979) approach to determining international monetary arangements as a two-stage game. In the first stage the rules are set; in the second, the policies are determined for the chosen set of rules.

${ }^{2}$ For examples of such models see some of the papers in Bhandari (1985).

${ }^{3}$ The objective functions (8): $\left(8^{\prime}\right)$ are well known to bave desirable welfare properties; see e.g. Aizenman and Frenkel (1985).

${ }^{4}$ Our analysie follows the usual monetary instrument literature by restricting the choice of alternative monetary instruments to the money stock and the interest ate. This restriction is somewhat arbitrary, since the monetary authorities can choose to control other aggregates as well. There are also other ways of conducting monetary policy such as adjusting the money stock to peg the price level. While this would be optinal in the face of aggregate demand shocks is and monetary shocks $v, v^{*}$, it would be an inappropriste policy for dealing with supply shocks. In any event, the approach of this paper can be adapted to analyzing an extended range of monetary policy instruments.

${ }^{5}$ One minor point is the familiax observation that under rational expectations, pegging the interest rate leads to an indeterminate mean price level. This is not serious, since the analysis focuses on deviations about equilibrium. Furthermore, the indeterminacy can be resolved by simultaneously setting a corresponding mean level for the money supply.

${ }^{6}$ For a discussion of Nash equilibrium in a bimatrix game see e.g. Basar and Olsder (1982), Frequently, a game may have more than one such equilibrium. In such cases a Nash equilibrium is said to be admissible if it is not dominated by some other equilibrium whick yields higher payofs to both agents. It is also possible for the bimatrix game to admit more than one admissible Nash equilibrium, in which case the equilibrium outcome becomes rather ill-defined and may involve conflicts; see Basar and Olsder for further discussion.

${ }^{7}$ These values are typical of those used in numerical sinulation studies; see e.g. Miller and Salmon (1985), Oudiz and Sachs (1985), Turnoviky and d'Orey (1986). 
${ }^{8}$ See e.g. Turnovsky (1984) for the derivation in the case of a small open economy. 


\section{REFERENCES}

Aizenman, J and J.A. Frenkel, 1985, "Optimal Wage Indexation, Foreign Exchange Intervention, and Monetary Policy, Americon Economic Review $75,402-423$

Basar, Tamer and Geet Olsder, 1983, Dynamic Noncooperative Game Theory, Academic Press Bhandari, Jagdeep S. (ed.), 1985, Ezchange Rate Management Under Uncertainty, MIT Press, Cambridge, MA.

Canzoneri, Matthew and Jo Anns Gray, 1985; "Monetary Policy Games and the Consequences of Noncooperative Behavior," Intepnational Economic Review 26, 547-564.

Farrell, J, 1987, "Cheap Talk, Coordination, and Entry," Rand Journal of Economics 18, $34-39$.

Hamada, Koichi, 1976, "A Strategic Analysie of Monetary Interdependence," Journal of Political Economy 84, 677-700. Miller, Marcus H, and Mark Salmon, 1985, "Policy Coordination and Dynamic Games ${ }_{y}^{n}$ in W.H. Buitez and R.C. Marston (eds.), International Economic Policy Coordination, Cambridge University Press, Cambridge, U.K

Mundell, Robert A, 1963, "Capital Mobility and Stabilization Policy Under Fixed and Flexible Exchange Rates, Conadion Journal of Economics and Political Science 29, 475-487.

Oudiz, Gilles and Jeffey Sachs, 1985, "International Policy Coordination in Dynamic Macroeconomic Models," in W.H. Buiter and R.C. Marston (eds.), International Economic Policy Coordination, Cambridge University Press, Cambridge, U.K.

Poole, Williarn, 1970, "Optimal Choice of Monetary Policy Instruments in a Single Stochastic Macro Model, Quarterly Journal of Economics 84, 197-216.

Turnovsky, S.J,, 1984, “Exchange Market Intervention Under Alternative Forms of Exogenous Disturbances," Journal of International Economics 17, 279-297.

Turnovsky, S.J. and Vasco d'Orey, 1986, "Monetary Policies in Interdependent Economies with

Stochastic Disturbances: A Strategic Approach, Economic Journal 96, 696-721. 